\section{How Sinister is Biology?}

Trie announcement two weeks ago of what seems to be a fairly reliable way of fertilizing human oocytes in vitro by Dr R. G. Edwards and his colleagues from the University of Cambridge seems to have conjured up once more the popular vision of malevolent science. A good many people seem to be ready to take sides even though the issues have not yet been defined with enough clarity for them to know what sides there are to choose. Energy has already been expended on a great many hypothetical questions, such as the likely impact on society of large numbers of identical individuals produced by the technique, so far demonstrated only with amphibians, of replacing the nuclear material of an egg cell with that taken from an intact coll of a grown individual. If speculation like this continues, it should not be long before the manuals on child care include separate chapters on the upbringing of the offspring of cloning. The trouble, of course, is that the speculation has so far outstripped reality as to be fantasy. It is therefore inevitable that reproductive physiologists, and even biologists in general, should find themselves the centre of popular suspicions.

In circumstances like these, it is important that there should be a much more clear appreciation of the practical difficulties of perfecting with human beings any of the techniques which seem to evoke visions of 1984 . The fertilization of human eggs outside the body is a good illustration. To begin with, it has yet to be demonstrated that the fertilized eggs can be grown successfully through tho first few days of life until they would normally implant themselves in the wall of the uterus, although animal exporiments would suggest that there can be no serious impediment here. But if the tochnique is ever to be used in attempts to avoid gross genetic malformations such as those associated with visible defects of chromosome pattern, it will be necessary to make some kind of examination of material taken from the blastocyst. But may this not entail a risk of genetic damage? And may not this risk be greater than that of letting nature take its course? At this stage, nobody can tell. What these uncertainties imply, however, is that the theoretical possibilities about which popular discussion centres may not bo practical possibilities at all. But if there are these problems with artificial fertilization, far greater uncertainties beset the technique of vegetative reproduction. The relatively tractable amphibian systems to which it has so far been applied demonstrate that with sufficient clarity. Genetic abnormalities seem to be much more frequent than successful development. Even if the technique is found to be unexpectedly successful with mammalian systems, there is likely to be an accompanying risk of malformation. At this stage, the chances are quite high that this risk would be unacceptable. In other words, cloning may be experimentally possible but practically inapplicable.

There should be no surprise at the width of the gulf between possibility and practice. Experience of the application of science is full of illustrations of how hopes and fears are frustrated by practical difficulties. The attempts to produce workable thermonuclear power sources are an example. So, should speculation wait on practical demonstration? This would be unfortunate, if only because speculation is a necessary part not merely of the attempt to estimate what will happen next but also of the processes by which people decide to commit their energies to particular projects. In the circumstances, there can be no substitute for a general appreciation of the difficulties which always attend the translation of an idea into practice. The most ironical feature of the current wave of public speculation about the potentialities of reproductive physiology is that it casts in a fearsome role a group of men and women who are if anything more devoted to humane objectives than their colleagues in other fields. Although the experiments of Dr Edwards and his colleagues are only the first successful step in what could become a sequence of investigations, a great deal of information on how abnormalities arise is likely to be forthcoming, for example. The public interest which the experiments have aroused is quite proper-even if flights of fancy have raised some frightening spectres-because there are undoubtedly serious questions which will sooner or later have to be answered. It is, however, essential that people should be armed with a true knowledge of what is and what is not going to be possible in the foreseeable future.

\section{VERTEBRATE PALAEONTOLOGY Lobe Finned Fishes}

from our Vertebrate Palaeontology Correspondent

THERE are three quite distinct types of lobe finned fish in the sub-class Sarcopterygii: the Dipnoi or lungfish, the almost extinct coelacanths and the wholly extinct rhipidistians. The sub-class is of special interest for several reasons, not least because it was from the rhipidistians that the land vertebrates evolved. There have been few studies of the Sarcopterygii as a whole, and the recent review of their biology by Thomson (Biol. Rev., 44, 91; 1969) is therefore particularly welcome

In both the Rhipidistia and the coelacanths, there is an intra-cranial joint and the respiratory current is produced by dorso-ventral movement of this joint, by lateral expansion of the cheek region and by dorsoventral pumping action of the hyoid apparatus. 